\title{
A IDEOLOGIA DO ACESSO ABERTO: O FETICHISMO DA TECNOLOGIA NA EDUCAÇÃO A DISTÂNCIA E A DIVERSIFICAÇÃO DA UNIVERSIDADE.
}

\author{
Alberico Francisco do Nascimento ${ }^{1}$
}

\begin{abstract}
RESUMO
Aborda-se a ofensiva neoliberal e a inserção das novas tecnologias de informação e de comunicação na área educacional e sua centralidade na formatação da universidade e da educação a distância a partir da LDB No 9.394/96. Trata-se de pesquisa bibliográfica cujo objetivo é demonstrar como o estado capitalista brasileiro através da aplicação do receituário neoliberal e de uma operação fetichista da tecnologia tem promovido a reconfiguração do formato da universidade brasileira e construído um modelo de "Universidade Organização". Discute-se a inserção da educação a distância na universidade, destacando os seguintes modelos de gestão que decorrem desse cenário: Universidade Aberta, Mista e os Consórcios de universidade.

Palavras-chave: políticas neoliberais; fetichismo; educação a distância.
\end{abstract}

\section{THE IDEOLOGY OF OPEN ACCESS: THE FETISHISM TECHNOLOGY IN DISTANCE EDUCATION AND THE UNIVERSITY DIVERSIFICATION.}

\begin{abstract}
Approaches the neoliberal offensive and the insertion of the new technologies of information and communication in education and its centrality in the formatting process of the university and distance education considering the LDB 9.394 / 96. It is a bibliographic research that aims to demonstrate how the Brazilian capitalist state through the application of neoliberal and a fetishist operation of technology has promoted the reconfiguration of the Brazilian university format and built a model of "University Organization". It discusses the insertion of distance education in the university, highlighting the following management models that follow from this scenario: Open University, Mixed and university consortium.
\end{abstract}

Keywords: neoliberal policies; fetishism; distance education.

\section{INTRODUÇÃOO}

A reestruturação produtiva do capitalismo global impõe uma nova realidade para o século XXI, que toma como base um cenário capitalista de competição globalizada, cujos elementos fundantes da produção e definidores de vantagens diferenciais são o conhecimento e o mercado. Essa nova realidade está assentada numa base econômica de acumulação flexível (Harvey, 1992) e tem como pressuposto uma sociedade técnicocientífico-informacional ou sociedade do conhecimento (Lojkine, 1995), centrada na produção através das novas tecnologias de informação e de comunicação e na elaboração de planejamentos estratégicos organizacionais inovadores. 
É nesse cenário, que a partir da década de 90, países periféricos como o Brasil foram intimados pela política internacional a efetuar a reforma do Estado - "Estado mínimo" - e, subjacente a esse quadro, na área educacional foi feita a reforma do sistema de ensino brasileiro através da Lei de Diretrizes e Bases da Educação Nacional - LDB n. ${ }^{\circ}$ 9.394/96 (BRASIL, 1996).

Com a Lei de Diretrizes e Bases da Educação Nacional novas e velhas questões educacionais vieram à tona aquecendo o debate acadêmico sobre os ranços e avanços da referida Lei. Dentre as questões polêmicas que a LDB suscita está a Educação a Distância - (EaD daqui em diante), que notadamente nas últimas décadas do século XX e no século XXI tem ocupado espaço relevante no conjunto das políticas educacionais implementadas pelo Estado capitalista brasileiro.

A implementação das recentes políticas públicas de $\mathrm{EaD}$ ganha força com a criação do Sistema Nacional de Educação a Distância em 1994 e se consolida com a regulamentação do Artigo 80 da LDB n. ${ }^{\circ}$ 9.394/96 e com a criação de órgãos públicos gestores na esfera federal, tais como: Secretaria da Educação a Distância (SEED) no Ministério da Educação (MEC), associações direta ou indiretamente relacionadas ao setor: ABED - Associação Brasileira de Educação a Distância e ABT - Associação Brasileira de Tecnologia Educacional, e diversas iniciativas educacionais vinculadas tanto ao setor público, quanto privado.

O projeto capitalista de transformar a EaD em uma proposta de educação em massa foi viabilizado pelas mídias produzidas por meio das novas tecnologias de informação e de comunicação ${ }^{2}$ já incorporadas no processo produtivo.

Diante desse contexto, este artigo analisa os determinantes implicados na consolidação da $\mathrm{EaD}$, como resposta do Estado e do capital à demanda das massas por ensino superior. Para isso tomo como ponto de partida o que há de mais concreto no fenômeno EaD, ou seja, sua base material: as novas tecnologias de informação e comunicação.

Diferente do caminho traçado pelos ideólogos da EaD que abordam tais tecnologias numa perspectiva linear e ahistórica, parte-se dos seus determinantes e das suas determinações no conjunto das relações sociais do Estado capitalista, a fim de analisa-las como uma totalidade operante não só na $\mathrm{EaD}$.

Esta análise baseou-se no entendimento das novas tecnologias como uma das formas em que o capital se concretiza no processo produtivo. Argumenta-se que as mesmas se inserem como uma nova forma de subordinação do trabalho, com base na relação orgânica entre Estado e o capital (SALAMA; MATHIAS, 1983), respaldada ideologicamente por meio da consolidação do ideário neoliberal nos países periféricos.

Considerando a relação orgânica entre Estado e capital, ressalta-se que, no conjunto das políticas neoliberais, o primeiro usa o aparato tecnológico como um mecanismo ideológico, para implementar o ajuste estrutural imposto pelos organismos internacionais e o segundo o faz com a finalidade de recompor suas taxas de acumulação, garantir o controle do processo produtivo e explorar novos nichos de mercado, como é o caso da esfera educacional via $\mathrm{EaD}$.

Decorre desse quadro que a presença das novas tecnologias de informação e comunicação é um fato concreto no conjunto das relações sociais no século XXI e sua inserção nas diversas áreas do conhecimento humano, tem desencadeado diferentes reações. Dentre as concepções de novas tecnologias há aquelas elaboradas com base nas 
suas relações com o conjunto da realidade social concreta e revelam sua relação direta com a produção capitalista, mas há também aquelas que se sustentam a partir de uma postura ufanista e as concebem apenas como um avanço, uma conquista da humanidade. Essas últimas concepções têm sido amplamente difundidas no imaginário dos sujeitos sociais pela ideologia dominante e estão presentes inclusive no âmbito acadêmico.

Uma amostra da concepção ufanista acerca das novas tecnologias pode ser encontrada em Brunner (2004) quando o mesmo sustenta que:

a revolução tecnológica da informação e das comunicações, uma das fontes das interconexões globais, representa, por si mesma, uma força transformadora de quase todos os âmbitos de atividade social: o trabalho e a produção, o lar e o consumo, o comércio, o entretenimento, a socialização e transmissão dos saberes, a organização das empresas e dos Estados, a oferta de serviços e a circulação de todo tipo de dados e conhecimentos (BRUNNER, 2004, p.22).

O autor supracitado fala em uma revolução tecnológica, autônoma e independente que redefine as relações sociais. Aponta as novas tecnologias como um fator de transformação da sociedade como um todo. Nessa concepção está implícita a ideia do fim do antagonismo entre as classes sociais, pois o trabalho e a produção serão transformados. O papel do Estado e a organização das empresas também serão redefinidos, uma vez que todos terão acesso a informações que antes eram privilégio de alguns poucos.

Partilhando dessa concepção ufanista a OCDE prevê que:

[...] as redes de comunicação e as aplicações interativas multimídias estão proporcionando os fundamentos para uma transformação das ordens socioeconômicas existentes, tendo em vista uma sociedade da informação. Esta é concebida como o resultado de uma mudança de paradigma nas estruturas industriais e relações sociais, semelhante à revolução industrial, que no seu momento transformou as sociedades agrárias (OCDE, 1997, p.7).

Essa posição reflete perfeitamente a profundidade com que os ideólogos das novas tecnologias abordam o assunto. Não se trata apenas de uma mudança pontual nesta ou naquela direção da sociedade, assegura o discurso ufanista, mas de uma transformação da própria estrutura socioeconômica da sociedade. Brunner (2004) chega inclusive a descrever as características dessa sociedade emergente. Segundo ele:

diversos autores caracterizam de diferentes maneiras essa sociedade emergente, mas lhe atribuem um conjunto de características comuns: está em processo de formação, adquiri gradualmente uma estrutura de redes, baseia-se na generalização e convergência das novas tecnologias de informação e comunicação, em particular a Internet; está dando lugar a economias que usam intensamente o conhecimento e, para funcionar com eficácia social, deverá adotar a forma de uma "sociedade de aprendizagem", que virá acompanhada de inovações organizacionais, comerciais, sociais e jurídicas; dará lugar a diversos modelos de desenvolvimento, cujo principal elemento diferenciador será o quanto integram ou excluem pessoas, grupos e nações; existirá uma maior demanda de flexibilidade em todos os planos, incluindo as oportunidades 
de formação, os mercados de trabalho e as relações sociais (BRUNNER, 2004, p. 22-23).

$\mathrm{Na}$ estrutura dessa sociedade emergente as novas tecnologias de informação e de comunicação são colocadas sempre à frente do processo de mudança; são a própria força motriz dessa "revolução". Sua generalização é direcionada à estrutura da sociedade na medida em que redefine os papéis sociais e cria uma sociabilidade que se apresenta como um suposto estágio superior do desenvolvimento social, pelo fato de trabalhar intensamente com o conhecimento.

Esse fenômeno social marcado pela louvação das novas tecnologias tem como suporte teórico-prático a ideologia do progresso técnico ${ }^{3}$ que se caracteriza pelo fato de procurar explicar os processos de transformação social a partir da introdução de novas tecnologias no campo da produção capitalista (ROMERO, 2005, p. 21; BRAGA, 1996, p. 82-83).

A concepção de progresso técnico elaborada pela ideologia dominante é de que as questões sociais que historicamente aprisionaram e limitaram o desenvolvimento da humanidade são superadas pela mediação das novas tecnologias. Essa dimensão ideológica da ação tecnológica é responsável pela ideia de que com as novas tecnologias de informação e de comunicação as pessoas podem realmente ser, fazer e ter mais do que sempre foram, fizeram e tiveram.

Inegavelmente as novas tecnologias já resolveram muitas questões que até então pareciam insolúveis, potencializaram os mais diversos campos científicos, diminuíram as distâncias no planeta e radicalizaram no nível de acesso às informações em geral. Porém, nada disso ocorreu sem que os interesses de classes estivessem presentes e determinassem cada avanço tecnológico.

No cotidiano, os sujeitos sociais vivenciam experiências nas quais o caráter inovador das novas tecnologias formata uma postura ideológica a favor de qualquer coisa que for agregada a esse fenômeno. Essa postura ideológica é uma aliada de primeira hora do Estado capitalista na dissimulação e socialização da proposta pedagógica de trabalho com EaD.

Diante desse quadro é que esta investigação problematiza a ação das novas tecnologias nas entranhas do sistema capitalista e tem a intenção de contribuir com a ampliação do horizonte investigativo nesse campo, suscitando questões que problematizam a EaD no cenário neoliberal. Sustenta-se o argumento de que o fetichismo é o artifício usado pelo capital para personificar as novas tecnologias no conjunto da sociedade e firmar a EaD no cenário educacional. E por fim aponta-se a reconfiguração do formato da universidade brasileira e a construção de um modelo de "Universidade Organização" que atende os critérios impostos pelas políticas neoliberais, dentre os quais se destacam os padrões quantitativos internacionais de educação superior impostos pelos organismos multilaterais.

\section{O AJUSTE NEOLIBERAL CONSENTIDO PELO ESTADO BRASILEIRO E A CONSOLIDAÇÃO DA EDUCAÇÃO A DISTÂNCIA}

Ao longo da história da educação brasileira tivemos duas Leis de Diretrizes e Bases da Educação Nacional, a LDBEN n. ${ }^{\circ} 4.024 / 61$ e a atual LDBEN n. ${ }^{\circ}$ 9.394/96. Entre essas duas LDBEN tivemos outras duas leis da educação a Lei n. ${ }^{\circ} 5.692 / 71$ e a Lei n. ${ }^{\circ} 5.540 / 68$, que apenas reformaram o ensino de $1^{\circ}$ e $2^{\circ}$ graus, assim denominado na época, e o Ensino 
Superior, respectivamente. Tais reformas se deram com a finalidade supra de adequar o sistema educacional brasileiro ao momento político ditatorial que o país vivenciava. A primeira LDBEN e as leis reformistas nem de longe sinalizaram um novo horizonte para a educação brasileira, quando muito podemos assegurar que na letra da lei havia um compromisso com a expansão quantitativa da rede de ensino e uma ênfase estimuladora e reguladora do ensino profissionalizante, em função do projeto desenvolvimentista que o país vivia, e, sobretudo, como forma de conter a demanda para o ensino superior.

Na década de 80, com as lutas pela redemocratização do país, consolida-se uma nova dinâmica social e política marcada pelas mobilizações sociais que já há algum tempo vinham se configurando. Na pauta das mobilizações sociais estava, dentre outras coisas, as dívidas sociais acumuladas e a luta pelos direitos sociais e políticos expropriados no período da ditadura militar.

O quadro acima citado culmina com a promulgação da Constituição de 1988, chamada de Constituição Cidadã, que procura assimilar em parte as demandas sociais da época e criar um ambiente de amplo espaço do exercício democrático no país. A educação, enquanto uma das demandas sociais presente naquela conjuntura, materializou-se no texto constitucional fundamentada nos pilares da universalização das oportunidades e da criação de novos espaços educacionais.

Entretanto, esse processo de ampliação de direitos sociais sinalizado pela Carta Magna de 1988 passa a ser duramente desconstruído a partir da década de 1990, quando o Estado brasileiro centraliza a orientação do seu desenvolvimento econômico com base no receituário neoliberal imposto pelos países industrializados e pelos organismos internacionais (Banco Mundial, BID, FMI, ONU, OMC, etc.).

Segundo Soares (2002), as políticas neoliberais são respostas às crises econômicas que os países industrializados experimentaram no século $\mathrm{XX}$ e cujas consequências se espalham pela economia internacional. O conceito de crise nesse contexto vai além da concepção negativa inerente ao próprio termo. Grespan (1998) atesta que é preciso entender esse conceito enquanto uma contradição constitutiva do capital, uma negatividade imanente ao capital e, Soares acrescenta:

Trata-se de uma crise global de um modelo social de acumulação, cujas tentativas de resolução têm produzido transformações estruturais que dão lugar a um modelo diferente - denominado de neoliberal - que inclui (por definição) a informalidade no trabalho, o desemprego, o subemprego, a desproteção trabalhista e consequentemente, uma "nova" pobreza (SOARES, 2002, p.12).

O ajuste neoliberal não se restringe ao setor econômico, faz parte de uma redefinição global do campo político-institucional e das relações sociais, dando origem também a um novo formato de Estado que tem a "nobre" função de promover políticas administrativas liberalizantes, privatizantes e de mercado, ou seja, a meta desse Estado é, sobretudo, diminuir o déficit fiscal e reduzir o gasto público (SOARES, 2002).

Esse Estado é fruto do discurso dos ideólogos burgueses que pregam a decadência do "estatismo" e "o retorno à ortodoxia" liberal (SOARES, 2002), entretanto, o Estado que emerge dessas mudanças no processo de acumulação mantém um forte caráter intervencionista, especialmente no tocante ao controle do trabalho e à formulação e implementação de políticas públicas (SILVA, 2003), portanto esse Estado só é mínimo para o trabalhador. 
Vale ressaltar que a mundialização do capital não se consolida com as mesmas características nos diversos países. Segundo Silva (2003) nas economias periféricas e semiperiféricas, como o Brasil, a transnacionalização não elimina, antes agrava, a relação de dominação centro/periferia presente em outros momentos.

No Brasil, a acolhida às orientações neoliberais intensificou no governo Fernando Henrique Cardoso (FHC), que criou um Ministério para essa finalidade, o Ministério da Administração e Reforma do Aparelho de Estado - MARE. A implantação de políticas liberalizantes e privatizantes pelo governo FHC não encontrou grandes resistências uma vez que o mesmo em função da sua postura político-ideológica contou com o apoio das classes burguesas e de uma coalizão de poder de centro-direita (SILVA, 2003).

Assim, em nome da governabilidade, foram desenvolvidas estratégias de controle da classe trabalhadora, de liberalização da economia para o setor privado em áreas que historicamente são de responsabilidade do Estado - como saúde, educação - e desconstrução do ainda precário sistema de proteção social conquistado com a Constituição cidadã. As políticas públicas que são formuladas a partir de então se constituem numa estratégia de transformar os serviços essenciais, ou seja, os direitos sociais, que devem ser garantidos pelo Estado, em uma mercadoria disponível num mercado altamente competitivo.

Segundo (SILVA, 2001, p.37) toda política pública é uma forma de intervenção na sociedade. E afirma ainda que políticas públicas "constitui um conjunto de ações ou omissões do Estado decorrente de decisões e não decisões, constituída por jogo de interesses, tendo como limites e condicionamentos os processos econômicos, políticos e sociais".

É nesse contexto que, em decorrência da Constituição de 1988, a LDBEN n. ${ }^{\circ}$ 9.394/96 é aprovada e a EaD passa a ser defendida pelo governo brasileiro como uma alternativa viável de democratização, expansão e inovação do sistema de ensino superior brasileiro.

É fundamental registrar que a até o final do século $\mathrm{XX}$ a grande maioria das Instituições de Ensino Superior no país não tinha envolvimento com EaD. Entretanto, a EaD não é uma modalidade de ensino nova, já que, desde 1923, com Edgard Roquette Pinto, criador da antiga Rádio Sociedade do Rio de Janeiro, são conhecidas iniciativas voltadas para sua disseminação.

Estas iniciativas, procurando novas tecnologias de comunicação que aproximassem a escola do público sem escola, utilizaram o rádio, com o Instituto Rádio Monitor em 1939; o correio, com o Instituto Universal Brasileiro em 1941, o que demarca a chamada $1^{\text {a }}$ geração da EaD; as décadas de 1970 e 1980 foram marcadas pelos cursos supletivos a distância no modelo de teleducação com aulas via satélite complementadas por kits de materiais impressos, falava-se da $2^{a}$ geração da EaD neste momento. A partir de 1990, o vídeo, a TV e o computador, e a Internet a partir de 1994 motivam a maior parte das IES brasileiras a se mobilizarem para a Educação a distância, era a chegada da $3^{a}$ geração da $\mathrm{EaD}$ (NUNES, 1994), que se consolidava como modalidade de ensino, com base nas novas tecnologias de informação e de comunicação, se consideramos as condições logísticas e, com a LDBEN 9.394/96, se considerarmos os aspetos relacionados à política educacional.

É com a LDBEN n. ${ }^{\circ}$ 9.394/96 fruto do ajuste neoliberal imposto pelos países imperialistas que a EaD converte-se em uma modalidade de ensino formal. A partir daí, o Estado capitalista brasileiro reestrutura a universidade, criando um suporte jurídico que vai 
legitimar e consolidar a $\mathrm{EaD}$ no Brasil. Concomitante à realização desse empreendimento neoliberal, articula ainda uma ofensiva fetichista do papel das novas tecnologias de informação e de comunicação, a fim de ocultar as contradições que inevitavelmente surgiriam com a diversificação do formato da universidade ao tomar a EaD como um de seus pilares.

\section{EDUCAÇÃO A DISTÂNCIA E A DIVERSIFICAÇÃO DA UNIVERSIDADE}

A partir da consolidação das políticas públicas de educação a distância que implicam na reestruturação da universidade, segundo Belloni (2003) podemos identificar três tipos de instituições, são elas: a universidade aberta, a universidade mista e as redes ou consórcios de universidades.

A universidade aberta ressalta Belloni, têm como referência as grandes universidades abertas da Europa: Open University britânca (UKOU), Universidad Nacional de Educación a Distancia espanhola (UNED), Fern Universität alemã, Universidade Aberta de Portugal, Open Universität da Holanda. Esse modelo de Universidades goza das mesmas prerrogativas das Universidades convencionais e seus diplomas têm o mesmo valor formal que os do ensino convencional.

Entretanto, o modus operandi dessas Universidades, de modo geral, diferencia-se das Universidades convencionais, pois de acordo com Belloni (2003) pauta-se,

segundo modelos mais ou menos industriais de produção e distribuição de cursos, apostando na economia de escala para otimizar os altos investimentos iniciais necessários a sua implantação. Estes modelos estão baseados na produção de um número relativamente pequeno de unidades de cursos utilizando "blocos multimeios" de materiais, cuja produção exige um volume relativamente importante de investimento em recursos humanos qualificados, recursos financeiros e técnicos. A viabilidade deste tipo de organização implica um grande número de estudantes, ou seja, um baixo custo unitário (BELLONI, 2003 p. 92).

As universidades abertas visam uma grande quantidade de alunos e uma produção em escala de materiais didáticos para garantir o equilíbrio da relação custo/benefício, ou seja, sua viabilidade econômica, para utilizar uma linguagem corrente no mercado neoliberal.

Ressalta-se também que o discurso oficial que justifica a utilização das novas tecnologias de informação e de comunicação se apoia na eficiência e na eficácia dessas ferramentas modernas, assim como na necessária inserção das novas gerações na moderna era digital. Entretanto, de acordo com Katz (1996), o emprego das novas tecnologias está diretamente associado ao aumento da exploração, ou seja, é um pretexto para intensificar o esforço de trabalho e ampliar seu volume não remunerado.

No Brasil existe atualmente a Universidade Aberta do Brasil - UAB, cujo projeto foi criado pelo Ministério da Educação em 2005 e em 2006 foi aprovada pela Casa Civil. A UAB funciona em parceria com algumas estatais brasileiras e utiliza as experiências de universidades públicas que já trabalham com a modalidade de educação a distância. De universidade a UAB tem apenas cursos, ensino a distância e novas formas de precarização do trabalho docente. O que está sendo chamado de Universidade Aberta pelo Ministério de Educação, na realidade se encaixa muito mais no modelo das redes e consórcios de universidades que atuam através da educação a distância. 
E isso não é novidade no panorama educacional brasileiro, uma vez que a partir de 1999 o Brasil já operava com consórcios e redes de cooperação universitárias para EaD voltadas para o ensino superior. Essas redes brasileiras de produção de cursos a distância fazem emergir o conceito de "Universidade Virtual". As três redes que surgem no período acima citado são: A UVB - Universidade Virtual Brasileira, um consórcio de dez instituições privadas e comunitárias; A Univir, voltada para o treinamento corporativo, e a UniRede - Rede de Universidades Públicas Brasileiras que reúne cerca de 62 instituições públicas de ensino superior.

De acordo com Trindade (1992) as redes ou consórcios caracterizam-se pela:

colaboração entre diferentes instituições educacionais, públicas ou privadas, e outras instituições não educacionais (empresas, órgãos oficiais nacionais, etc.), que se constituem para oferecer serviços e produtos de educação e formação a distância para seus associados, para corporações externas ou usuários individuais (TRINDADE, 1992. p.88).

Esses consórcios, idealizados a partir das políticas de mercado neoliberais, representam uma nova face da universidade, que passa a desenvolver suas atividades inspirada na estratégia das grandes empresas nacionais e internacionais que se fundem formando poderosos grupos investidores e manipuladores do mercado. $\mathrm{O}$ grande objetivo desses empreendimentos é a otimização de recursos e o atendimento e domínio das demandas do mercado. Segundo Chauí apud Dourado (2003),

nos anos 90 a universidade brasileira assume uma face operacional, ou seja, ela volta-se para si mesma como estrutura de gestão e de arbitragem de contratos e, nesse sentido, assume o perfil de uma organização de tipo capitalista (DOURADO, 2003, p. 35).

$\mathrm{Na}$ ótica da doutrina capitalista, a universidade precisa vincular sua produção acadêmica às necessidades do mercado e do capital para se manter enquanto agência produtiva. Esse entendimento foi o motor da reforma educacional que culminou com a aprovação da LDB 9.394/96 e no que diz respeito à educação superior abriu um leque de opções estratégicas para que a mesma pudesse se inserir na lógica da produção capitalista.

Uma dessas estratégias está registrada na Portaria n..$^{\circ}$ 253/01 do MEC que torna possível, em cursos superiores de universidades convencionais, a oferta de disciplinas, em seu todo ou em parte, através da utilização do método não presencial, educação a distância, até o limite de $20 \%$ da carga horária de integralização do currículo.

É nesse cenário que surgem as universidades mistas, que estão representadas na sua maioria por instituições privadas de ensino superior que convertem parte da carga horária dos seus cursos presenciais em aulas virtuais ou que se associam a instituições que já atuam no "mercado" da educação a distância.

Essa possibilidade sinalizada pela Portaria acima citada tem resultado em verdadeiras armadilhas para os alunos das IES privadas, que geralmente não têm acesso ao Projeto Pedagógico dos cursos dessas instituições, ou quando têm não dimensionam o impacto de tais metodologias para a sua formação acadêmica.

A implementação de sistemas mistos nas IES particulares e públicas é na verdade uma resposta perversa do estado capitalista à lógica de otimização de custos e maximização da margem de lucro imposta pelo mercado capitalista, que dentre outras 
questões sacrifica o emprego de centenas de professores que são substituídos por tutores horistas. Diante desse quadro é oportuno analisar o pensamento de Belloni (2003) ao chamar atenção para o fato de que:

É importante lembrar que a expansão da EaD na última década representa muito menos o "triunfo da ideologia do acesso aberto" à educação e muito mais o impacto das forças de mercado e da situação de recessão econômica e consequentes políticas governamentais de restrição de recursos aplicados à educação (BELLONI, 2003 p. 99).

A diversificação do ensino superior via EaD pauta-se na lógica do que é viável ao mercado capitalista e, nesse sentido, os ideólogos do grande Leviatã capitalista se empenharam em construir, através do fetichismo tecnológico, uma nova identidade do cotidiano acadêmico universitário que descaracteriza a concepção de universidade enquanto locus acadêmico de ensino, pesquisa e extensão, reestruturando essa instituição a um empreendimento genuinamente capitalista. Um empreendimento eficiente porque usa tecnologias eficientes, capazes de revolucionar não só as formas de ensinar e aprender, mas a própria vida em sociedade e criar um novo paradigma tecnosocial no imaginário dos sujeitos consumidores desses bens e serviços.

\section{O FETICHISMO DA TECNOLOGIA COMO RECURSO DE PROMOÇÃO DA EDUCAÇÃO A DISTÂNCIA}

Quando a questão é a análise do uso das novas tecnologias na educação, a ideologia do progresso técnico, disseminada através da sociabilidade capitalista ofusca as nuances dessa investigação e simplifica a dissociação entre modelo social e base material. Nesse contexto, o uso das novas tecnologias em geral e especificamente, na educação passa a ser considerado somente no quesito da superação técnica das práticas produtivas, sociais e educacionais, sem que se faça alguma relação das implicações sociopolíticas resultantes da sua aplicação na sociedade.

Tal fato remete à seguinte afirmação: abordar as novas tecnologias apenas como artefatos que facilitam a vida das pessoas e promovem o progresso técnico da sociedade é uma operação ideológica sustentada pelo fenômeno do fetichismo na conjuntura da reestruturação produtiva do capital.

Mas o que é fetichismo? Segundo Abbagnano (2000, p. 439), o termo fetichismo é em geral empregado pelos filósofos em sentido depreciativo e significa "crença no poder sobrenatural ou mágico de certos objetos materiais". Saindo do campo etimológico para o campo das relações sociais, na sociedade capitalista tem-se que a palavra fetichismo foi utilizada por Marx ao analisar o processo de produção da mercadoria no primeiro livro de O capital (1998). Na concepção marxista, fetichismo é a transferência do foco da análise das relações sociais para as coisas em si, ou seja, é o modo pelo qual as formas econômicas do capitalismo ocultam as relações sociais a elas subjugadas.

A expressão Fetichismo da mercadoria foi usada por Marx, a fim de elucidar o conteúdo de classe da produção no capitalismo e mostrar que a mercadoria não é uma forma de produção natural, que perpassa toda a história da humanidade. Para Marx, a sociedade capitalista transforma a relação social entre os homens atribuindo características de relação entre coisas. Uma passagem do livro $O$ capital é bem representativa desse fenômeno: 
O misterioso da forma mercadoria consiste simplesmente no fato de que ela reflete aos homens as características sociais do seu próprio trabalho como características objetivas dos produtos do trabalho, como propriedades naturais sociais dessas coisas e, por isso, também reflete a relação social existente fora deles, entre objetos (MARX, 1998, p. 198).

Fetichismo não é simplesmente feitiço, encanto, mas é uma inversão do sujeito em objeto, é a personificação ideológica das coisas e a objetificação do sujeito. Nesse processo de inversão, o fetichismo estabelece uma dicotomia entre a aparência e a realidade, de tal forma que esta última dimensão é dissimulada pela ação ideológica do fetiche (MARX, 1998).

A aparência do fenômeno, personificada nele mesmo, portanto real, adquire atributos do fenômeno em sua totalidade, dissimulando a relação entre os produtores, ou seja, entre o capitalista, os trabalhadores e os processos econômicos resultantes dessa relação produtiva. É nesse contexto que, segundo Feenberg (1999), o preço é colocado como um atributo da mercadoria, obstruindo a percepção das questões sociais e econômicas implicadas em sua produção:

No uso marxiano, o fetichismo das mercadorias não é a atração pelo consumo, mas a crença prática na realidade dos preços colocados nas mercadorias pelo mercado. Como destaca Marx, o preço não é, de fato, um atributo "real" (físico) das mercadorias, mas a cristalização de uma relação entre os fabricantes e os consumidores. No entanto, o movimento das mercadorias do vendedor para o comprador é determinado pelo preço como se ele fosse real (FEENBERG, 1999. p. 28).

Da mesma forma que o capital através do seu aparato ideológico encobre na mercadoria a relação de classes de uma época historicamente determinada, constrói também uma concepção de tecnologia, que é apresentada e assimilada como ciência aplicada destituída de seu caráter de classe, capaz de revolucionar a vida em sociedade, de criar um novo paradigma educacional e de aumentar a eficiência na produção de bens e serviços.

A análise do fetichismo da tecnologia a partir de uma construção histórico-social, permeada pela luta de classes que historicamente tem marcado a humanidade mostra o caráter político supostamente neutro, sujeito a valores estritamente técnicos atribuído às novas tecnologias de informação e de comunicação pela ideologia dominante.

Parafraseando Feenberg (1999), afirma-se que fetichismo da tecnologia é a crença prática na utilização das novas tecnologias no mercado como uma possibilidade concreta de democratização do acesso a serviços e produtos antes restritos a uma pequena parcela de privilegiados. Feenberg sustenta ainda que "o que se mascara na percepção fetichista da tecnologia é seu caráter relacional, justamente porque ela aparece como uma instância não social de pura racionalidade técnica" (FEENBERG, 1999. p.28).

O fetichismo da tecnologia, portanto, está para além do encanto virtual cujo "feitiço digital" vinculado a um determinado produto, fruto da microtecnologia (celular, pendriver, MPs, notebook, netbook, ipod, microsensores, microrobores, etc.) contagia as pessoas, tornando-as consumidoras e usuárias compulsivas de produtos e serviços tecnológicos que parecem dotados de vida própria, de plena autonomia. Igualmente, no campo pedagógico, o fetichismo tecnológico não é a simples informatização da escola e da universidade; a 
mediação das práticas didático-pedagógicas pelo computador; a possibilidade de pesquisar on line e de usufruir do armazenamento virtual de dados.

Essa relação encantadora entre as tecnologias e os seres humanos não representa o fetichismo da tecnologia. Porém é importante registrar que suas características futuristas, utilitárias, inovadoras e "mágicas" são partes de um apelo ideológico fundamental para sustentar o caráter fetichista, na medida em que sua sustentação está diretamente vinculada aos elementos descritivos das tecnologias, ou seja, à sua aparência e ao seu conteúdo técnico.

O fetichismo tecnológico é a mistificação das questões sociais e, no âmbito da educação, das questões educacionais. É a crença nas novas tecnologias como uma possibilidade de reversão da opressão social, política, econômica e educacional. É a crença no poder da técnica em detrimento das lutas sociais. É a visão das novas tecnologias como uma panaceia, ou seja, um remédio para todos os problemas e para o problema de todos.

Nessa perspectiva, tecnologizar a educação e o conjunto da vida social, através da coerção ideológica do pensamento dominante, significa a articulação de novas formas de subordinação que colocarão o Estado e o capital em posições cada vez mais blindadas e não menos contraditórias, no contexto de uma intensa luta contra a classe trabalhadora que também busca suas formas de resistência e de enfretamento.

$\mathrm{O}$ fetichismo tecnológico atribui às novas tecnologias um caráter ahistórico e antissocial, reduzindo-as a uma dimensão tecnicista. No espaço educacional, o fetichismo tecnológico é um recurso limitado e superficial utilizado na sociedade capitalista para ocultar as contradições decorrentes do processo de massificação da EaD.

É preciso registrar que a questão a qual se coloca nesse momento não diz respeito ao uso da tecnologia em si, ou seja, sua forma e seu conteúdo, mas à forma específica que a relação tecnologia e o seu uso no processo educativo assumem no conjunto das relações capitalistas. Essa distinção é necessária porque não há identidade entre capital e tecnologia, ou seja, o capital não é a condição sine qua non para o progresso tecnológico. O capital é a condição fundamental para o progresso tecnológico aplicado na produção capitalista (KATZ, 1996). Ao longo da história da humanidade, a inovação tecnológica sempre foi um fato concreto e continuará sendo independente do modelo socioeconômico vigente. $\mathrm{O}$ desenvolvimento das técnicas de trabalho pelo ser humano representa a própria evolução da espécie humana na sua relação com a natureza e com seu semelhante.

Não obstante a esse processo permanente de transformação da natureza e criação de novas técnicas, métodos e instrumentos, que ampliam a capacidade de ação da humanidade, as tecnologias estarão sempre limitadas à sua finalidade técnica, ou seja, ao benefício prometido.

Máquinas não criam valores e muito menos geram lucros. Somente quando submetidas aos parâmetros capitalistas de maximizar o lucro é que a dinâmica tecnológica passa a incorporar princípios estranhos e opostos ao seu próprio desenvolvimento (KATZ, 1996. p. 97).

No contexto capitalista, as tecnologias não são uma totalidade em si, mas uma dimensão do capital (ROMERO 2005). O foco não é o que um determinado artefato tecnológico pode fazer ou deixar de fazer, mas o objetivo que esse artefato assume, na proporção que compõe o conjunto dos meios de produção da sociedade capitalista. No capitalismo, os recursos tecnológicos enquanto meios de produção só tem sentido para o 
capitalista na medida em que são aplicados, visando à maximização da valorização do capital. Como afirma Romero (2005):

No capitalismo, a técnica não é apenas um instrumento de trabalho, como ocorria nas formações sociais pré-capitalistas, mas um instrumento do processo de valorização, implicando e determinando uma relação específica de domínio e de exploração do trabalhador (ROMERO, 2005, p.124).

As implicações, dessa análise, no setor educacional indicam que as práticas de $\mathrm{EaD}$, apoiada nas novas tecnologias implementadas tanto no setor público como no privado, são expressões de uma reterritorialização do trabalho educativo $(\mathrm{EaD})$ e reinvenção do trabalhador educador (Tutor), marcada pela redução dos gastos do Estado e pelo processo de valorização do capital. Enquanto o Estado investe menos; o capital se valoriza mais, e o faz respaldado pelo aparato institucional legal criado pelo primeiro.

Com a utilização massiva de $\mathrm{EaD}$ via novas tecnologias na universidade, as políticas neoliberais põem em prática um plano de precarização do oficio de educador ao passo em que oficializa a figura do tutor. A "recriação" do trabalhador educador torna-se uma necessidade estratégica do capital imposta pelos organismos internacionais que, após um intenso processo de desqualificação do espaço acadêmico, amparado pelo Estado capitalista, agora reinventam as formas de trabalho pedagógico nos sistemas de ensino dos países latinos sob o argumento da busca de eficiência que o Estado não conseguiu alcançar.

No cenário tecnológico criado pelo Estado capitalista, o trabalho educativo na universidade, é visto como inovador e criador de espaços acadêmicos autônomos, avançados. Trata-se de uma autonomia para o Estado e para o capital, e não para o trabalhador. A inovação é o horizonte desse contexto e o capital, na sua relação orgânica com o Estado, dá aparência de universal ao que é particular, ao que é interesse apenas para as frações de classe da burguesia.

A análise das novas tecnologias no campo do materialismo histórico-dialético é uma possibilidade concreta de ir além da ideologia que alimenta o fetichismo tecnológico e compreender as implicações sociais da inserção das novas tecnologias no setor educacional. Ultrapassam-se os limites estabelecidos pelo fetichismo tecnológico e remetese o debate para "a análise da forma material adotado pelo desenvolvimento das forças produtivas" (KATZ, 1996, p.9) e para o campo das lutas de classes que se materializam nas estruturas de controle da produção capitalista.

Enfim, quando a base da análise é o processo de produção e não o âmbito da circulação como fazem os ideólogos da burguesia, pode-se ir além do fetichismo da tecnologia compreendendo que este é uma dissimulação, da real finalidade das novas tecnologias aplicadas na EaD. Cabe lembrar que "nenhum tipo de desenvolvimento tecnológico implantado no modo de produção capitalista pode eliminar a subordinação estrutural necessária do trabalho ao capital” (MÉSZÁROS, 2002, p. 99).

\section{CONSIDERAÇÕES FINAIS}

A nova identidade gerada no ensino superior que coloca a universidade e as IES brasileiras na condição de organizações capitalista foi implantada efetivamente a partir da aprovação da atual Lei de Diretrizes e Bases da Educação Nacional - LDB n. ${ }^{\circ} 9.394$ de 
1996. A referida lei traz no seu escopo apenas um Artigo (Art. 80) sobre o uso das novas tecnologias da informação e da comunicação e a educação a distancia.

Esse Artigo aborda genericamente o assunto, deixando as questões mais relevantes para serem regulamentadas a posteriori a partir das negociações e dos lobbiesarticulados pelos deputados, senadores e suas bancadas. Considerando que a campanha desses deputados e senadores é patrocinada por setores empresariais que tem interesse direto no assunto, pode-se deduzir qual a direção político-ideológica que a regulamentação de questões de interesse da educação nacional tem tomado.

No dia 19 de dezembro de 2005 entrou em vigor o Decreto $\mathrm{n}^{\circ}$. 5.622 que regulamenta o Artigo 80 da LDB. Esse Decreto juntamente com a criação da Universidade Aberta do Brasil, já citada neste trabalho, representa a mão (in)visível do Estado capitalista brasileiro impondo a Educação a Distância à posição de metodologia amplamente reconhecida e regulamentada para todos os níveis de ensino, como forma de suplantar as críticas e as lutas legitimas dos intelectuais e educadores brasileiros por uma educação presencial de qualidade e por uma universidade presencial, verdadeiramente democrática, moderna, equipada com instrumentos que representam as novas tecnologias da informação e da comunicação capazes de ampliar o horizonte do ensino presencial, da pesquisa e da extensão.

As próximas décadas deste século nos reservam grandes embates, pois, como nos mostrou Marx (2001) no manifesto do Partido Comunista, a burguesia não pode existir sem renovar permanentemente as forças produtivas. Assim sendo, está posto o desafio de ampliar as trincheiras de lutas pela justiça social e denunciar a hibridização do ensino superior e a conseqüente metamorfose da universidade como uma nova investida da sociedade burguesa contra os direitos sociais dos trabalhadores. 


\section{REFERÊNCIAS}

ABBAGNANO, Nicola. Dicionário de Filosofia. São Paulo: Martins Fontes, 2000.

BRASIL. Lei n. 9.394/96, de 20 de dezembro de 1996, que estabelece as diretrizes e bases da educação nacional. Brasil, 1996.

BRAGA, R. A restauração do capital. São Paulo. Xamã, 1996.

BELLONI, Maria Luiza. Educação a Distância, Campinas, Editora Autores

Associados, 2003.

BRUNNER, J. J. Educação no encontro com as novas tecnologias. In:

TEDESCO, C. J. Educação e novas tecnologias: esperança ou incerteza? São Paulo: Cortez; Buenos Aires: Instituto Internacional de Planejamento de la Educacion; Brasília: UNESCO, 2004.

DOURADO, L. F.; CATANI, A. M.; OLIVEIRA, J. F. DE. (Orgs.) Políticas e gestão da educação superior: transformações recentes e debates atuais. São Paulo: Xamã; Goiânia; Alternativa, 2003.

FEENBERG, A. “A filosofia da tecnologia numa encruzilhada”. 1999. [Tradução de Newton Ramos de Olieira] Disponível em: <htpp//WWW.

Rohan.sdsu.edu/faculty/feenberg>. Acessado em: 24 de jan de 2015.

GRESPAN, Jorge Luis da Silva. O negativo do capital: o conceito de crise na crítica de Marx à economia política. São Paulo: Hucitec, 1998.

HARVEY, D. Condição Pós-Moderna. São Paulo: Loyola, 1992.

KATZ, Claúdio (Org). Novas tecnologias: crítica da atual reestruturação produtiva. São Paulo: Xamã, 1995.

LOJKINE, Jean. A revolução informacional. São Paulo Cortez, 2002.

MARX, Karl. O capital: crítica da economia política: Livro I: O processo de produção do capital. 16. ed. Tradução Reginaldo Sant'Anna. Rio de Janeiro: Civilização Brasileira, v. 2, 1998.

MARX, Karl; ENGELS, Friedrich. O manifesto do partido comunista. Porto Alegre: L\&PM, 2001.

MÉSZÁROS, I. Para além do capital: rumo a uma teoria da transição. Tradução de Paulo César Castanheira e Sergio Lessa. São Paulo: Boitempo: Edinicamp, 2002.

NUNES, Ivônio Barros. Noções de Educação a Distância. In: Revista Educação a Distância, Brasília, Instituto Nacional de Educação a Distância, rev. INED/UnB-CEAD, 03 (04/05) pp.07-25, Dez./93-Abr/94. 
ROMERO, Daniel. Marx e a técnica: um estudo dos manuscritos de 1861 - 1863. São Paulo: Expressão popular, 2005.

SALAMA, Pierre. MATHIAS, Gilberto. O Estado superdesenvolvido: ensaios sobre a intervenção estatal e sobre as formas de dominação no capitalismo contemporâneo. São Paulo, Editora Brasiliense, 1983.

SILVA, Ilse Gomes. Democracia e participação na "reforma" do estado. São Paulo, Cortez, 2003.

SOARES, Laura Tavares. Os custos sociais do ajuste neoliberal na América Latina. São Paulo, Cortez, 2002.

SILVA, Maria Ozanira da Silva e. (coord.) Avaliação de políticas e programas sociais: teoria e prática. São Paulo: Veras, 2001.

TRINDADE, Armando. Fundamentos da Educação a Distância: panorama conceitual da educação e do treinamento a distância. Trad. José Geraldo Campos Trindade. In: Distance Education for Europe. 2ed. Lisboa: Universidade Aberta , 1992.

1 Professor adjunto do Instituto Federal de Educação Ciência e Tecnologia do Maranhão - IFMA Campus São Luís - Monte Castelo. Membro do Grupo de Estudos e Pesquisas História, Sociedade e Educação no Brasil - HISTEDBR, GT MA. E-mail: alberico@ifma.edu.br.

2 Novas são aquelas tecnologias que não se confundem com as "velhas": lousa, caderno, lápis, caneta, livros didáticos, etc. Novas, assim, são as tecnologias de informação e de comunicação (TIC), em uma formulação que demarca o seu pertencimento a áreas não-educacionais, no sentido de produzidas no contexto de outras relações sociais e para outros fins (BARRETO, 2003, p.273).

3 A ideologia do progresso técnico põe em evidência o que as novas tecnologias podem fazer pela sociedade, mas não discute a organização da sociedade que supostamente é transformada pelas novas tecnologias. Tratam o assunto como se as transformações tecnológicas na sociedade capitalista fossem uma resposta iluminada do seu próprio desenvolvimento. Como se as determinações do desenvolvimento tecnológico pudessem ser compreendidas para além das formações sociais de cada época, ou seja, para além da história. Como se o desenvolvimento tecnológico fosse ele próprio a determinação do movimento histórico (ROMERO, 2005).

Recebido: jun/2015 $\quad$ Aprovado: jul/2015 